\title{
AN INVESTIGATION OF EME AS A POTENTIAL CAUSE OF FUEL TANK IGNITION
}

\author{
Jay J. Ely, Truong X. Nguyen, Kenneth L. Dudley, Stephen A. Scearce, Fred B. Beck, Manohar D. \\ Deshpande and C. R. Cockrell: NASA Langley Research Center, Hampton, Virginia
}

\begin{abstract}
NASA researchers were tasked to study the potential for radio signals to excite an aircraft fuel quantity indication system (FQIS) enough to cause arcing, sparking or excessive heating within a fuel tank. Computational techniques were used to determine the threat from external high intensity radiated field (HIRF) transmitters nearby, like shipboard and airborne RADAR systems. Experimental methods were used to determine the threat from Portable Electronic Devices (PEDs) carried aboard by passengers. To support this work, unique electromagnetic coupling measurements were performed on a retired Boeing 747 aircraft, and new test and analysis methods were developed that may be applied to other FQIS designs as well as other aircraft electronic systems.
\end{abstract}

\section{Introduction}

On July 17, 1996, the Trans World Airlines Flight 800 (TWA-800) Boeing 747 Series 100 (B747-100) aircraft exploded and crashed into the Atlantic Ocean. The flight had departed 14 minutes earlier, traveling from New York's John F.

Kennedy airport to Paris. To date, it is believed that a fuel vapor ignition occurred in the center wing fuel tank (CWT). The cause of this ignition is still unresolved.

During the first year of the investigation, some consideration had been applied to the possibility of man-made electromagnetic interference as a factor in the crash. Later, in April, 1998, a special supplement entitled "The Fall of TWA 800: The Possibility of Electromagnetic Interference" was published in The New York Review of Books, by Harvard professor Elaine Scarry [1]. This report, along with continued dialog between Ms. Scarry and NTSB Chairman Jim Hall, prefaced an increased desire to quantify the actual threat from external high intensity radiated field (HIRF) sources. The electromagnetic environment surrounding TWA-800 was rather complex, and included numerous ground-based, shipboard, and airborne radio frequency (RF) transmitters, some being classified by the military. As a result, the Department of Defense (DoD) Joint Spectrum Center (JSC) was contracted to perform a detailed analysis of the TWA-800 electromagnetic environment. Their report was published in January 1999, and incorporated into the NTSB TWA Flight 800 Public Hearing Exhibit Items as Exhibit 9A, Addendum 2 [2]. The JSC reported that all dominant, external RF emitters were pulsed sources, applying peak field intensities of up to 32.6 $\mathrm{V} / \mathrm{m}$ to the airspace of TWA- 800 .

Alternatively, it can be demonstrated that a portable radio transmitting about $5 \mathrm{~W}$ may generate field levels in excess of $100 \mathrm{~V} / \mathrm{m}$ very close to its antenna. When used inside an aircraft, portable electronic devices (PEDs) can be placed within inches of aircraft wiring, and their emissions are not subject to airframe attenuation as are outside HIRF sources. NASA's Aviation Safety Reporting System (ASRS) documents numerous occurrences of suspected PED interference with aircraft systems.

Very little quantitative information is available regarding specific frequency-power-temperaturepressure combinations required for hazardous conditions with aviation fuels. The DoD has documented the threat to fuel and ordinance from hand-held transmitters with output power capabilities of as little as $1 \mathrm{~W}$ [3].

Because of the known volatile state of CWT fuel vapor, the complex RF environment, and minimal degree of RF shielding on the FQIS wiring of Classic Boeing 747-100 aircraft, the NTSB decided to investigate the potential for man-made electromagnetic environment (EME) to cause the TWA-800 fuel tank ignition. 


\section{Quantifying the Problem}

Using Figure 1 as a guide, three independent variables can be identified as follows:

$A(f)=$ Electromagnetic emission threat power (HIRF or PED Source )

$B(f)=$ Coupling factor from source to fuel tank wiring (Path Factor)

$\mathrm{C}(\mathrm{f})=$ Minimum RF Power required to cause ionization/heating event in fuel tank (Event Power)

Each of these variables is dependent upon the frequency (f) of interest. Essentially, B(f) is a transfer function that operates upon $\mathrm{A}(\mathrm{f})$, and the three terms can be related by:

$$
A(f) \cdot B(f) \geq C(f)
$$

If Equation (1) is true, there is the potential for RF-induced fuel vapor ignition.

The analysis approach was to use computational methods to evaluate the external HIRF threats, and experimental methods to evaluate internal PED threats.

\section{External Analysis (Computational)}

The Joint Spectrum Center analysis of the TWA-800 electromagnetic environment provided answers for external A(f), adjusted for minimum possible propagation loss to the accident location.

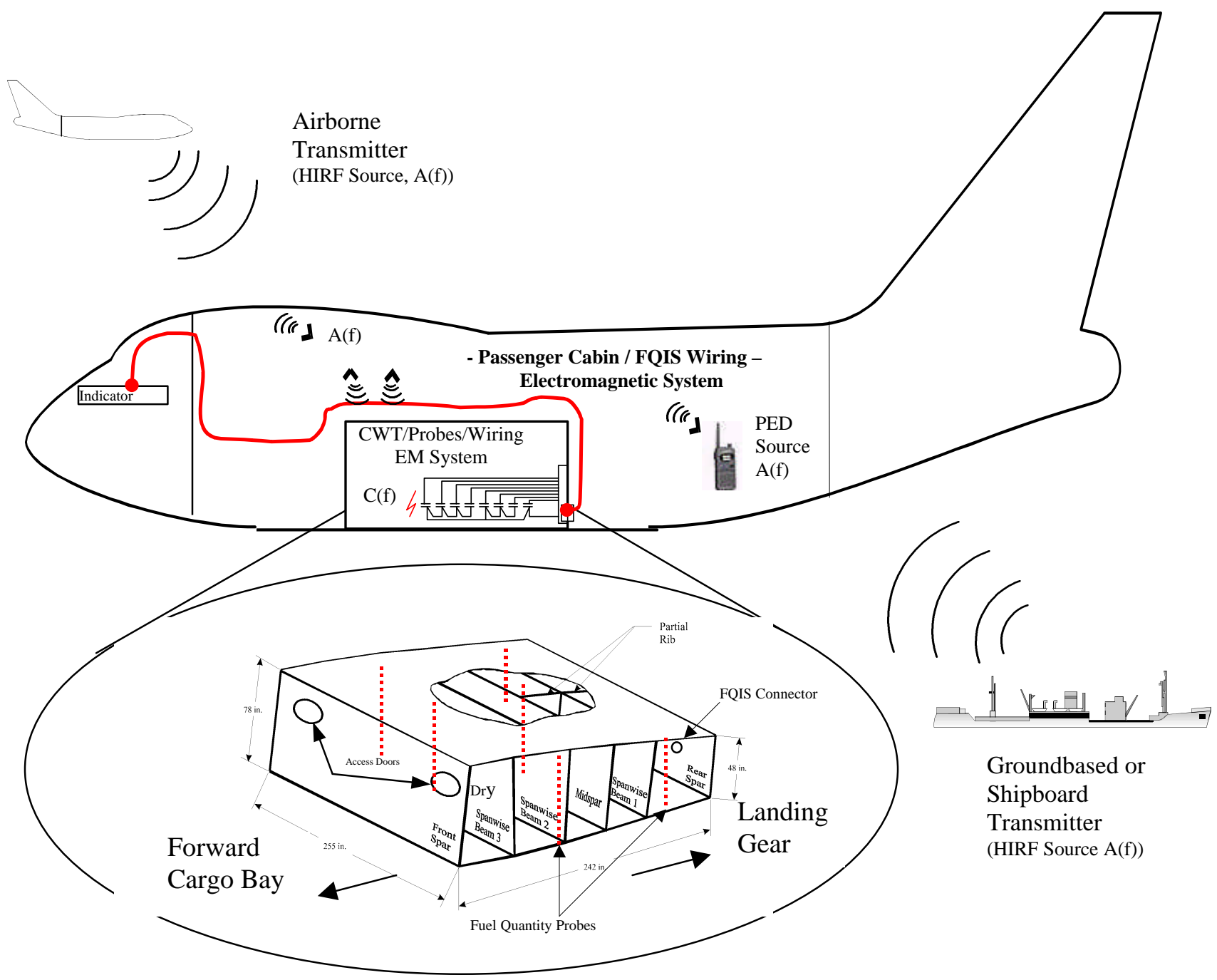

Figure 1. RF Coupling to Aircraft Fuel Tank 


\section{Maximum Available Energy Inside Passenger Cabin}

Using the maximum field strengths from signal sources identified by the JSC as dominant emitters, the maximum energy available inside the aircraft passenger cabin for each source was estimated, and is summarized in Table 1. These dominant emitters were all pulsed sources, allowing the threat to be quantified in terms of energy, instead of power.

Table 1: TWA-800 Environment Dominant Emitters

\begin{tabular}{|c|c|c|c|c|c|c|}
\hline $\begin{array}{c}\text { Frequency } \\
(\mathbf{G H z})\end{array}$ & 1.294 & 2.875 & $\begin{array}{l}3.1- \\
3.5\end{array}$ & $\begin{array}{l}3.1- \\
3.5\end{array}$ & $\begin{array}{l}8.5- \\
9.6\end{array}$ & 9.1 \\
\hline Description & $\begin{array}{l}\text { Riverhead, } \\
\text { NY Search } \\
\text { RADAR }\end{array}$ & $\begin{array}{l}\text { Brook- } \\
\text { haven, NY } \\
\text { Weather } \\
\text { RADAR }\end{array}$ & $\begin{array}{l}\text { Shipboard } \\
\text { Search } \\
\text { RADAR }\end{array}$ & $\begin{array}{l}\text { Moores- } \\
\text { town, NJ } \\
\text { Search } \\
\text { RADAR } \\
\end{array}$ & $\begin{array}{l}\text { Airbome } \\
\text { Search } \\
\text { RADAR }\end{array}$ & $\begin{array}{l}\text { Calver- } \\
\text { ton, NY } \\
\text { Tracking } \\
\text { RADAR }\end{array}$ \\
\hline EIRP (dBm) & 128.0 & 134.8 & 136.0 & \begin{tabular}{|l|}
139.8 \\
\end{tabular} & 117.4 & 128.0 \\
\hline Gain (dBi) & 35 & 46 & 38 & 42 & 34 & 44 \\
\hline $\begin{array}{l}\text { Distance } \\
(\mathrm{nmi})\end{array}$ & 13.1 & 15.7 & 156.3 & 112.0 & 2.93 & 17.0 \\
\hline $\begin{array}{l}\text { Pulse Width } \\
(\mu s e c)\end{array}$ & 2.0 & $1.0,4.0$ & $6.0,51.0$ & $6.0,51.0$ & 2.5 & 2.0 \\
\hline $\begin{array}{l}\text { PRF } \\
\text { (Pulses/sec) }\end{array}$ & 341 & 1300,320 & 1840,152 & $\begin{array}{l}1840, \\
152 \\
\end{array}$ & 400 & 300 \\
\hline Duty Cycle & 0.00068 & 0.0013 & 0.011 & 0.011 & 0.001 & 0.0006 \\
\hline Polarization & & HorV & $\mathrm{V}$ & $\mathrm{V}$ & & $\mathrm{V}$ \\
\hline $\begin{array}{l}\text { Power Density } \\
\left(\mathrm{dBm} / \mathrm{m}^{2}\right)\end{array}$ & 29.304 & 34.531 & 15.77 & 22.465 & 31.712 & 26.989 \\
\hline $\begin{array}{l}\text { Field Intensity } \\
(\mathrm{V} / \mathrm{m})\end{array}$ & 17.921 & 32.713 & 3.773 & 8.155 & 23.646 & 13.727 \\
\hline $\begin{array}{l}\text { Energy } \\
\text { Density } \\
\left(\mu \mathrm{J} / \mathrm{m}^{2}\right) \\
\end{array}$ & 1.704 & 11.355 & 1.933 & 9.031 & 3.708 & 1.00 \\
\hline $\begin{array}{l}\text { Energy } \\
(\mathrm{mJ}) *\end{array}$ & 0.015 & 0.097 & 0.017 & 0.077 & 0.032 & 0.009 \\
\hline
\end{tabular}

* Assuming window surface area $=98 \times 0.0875 \mathrm{~m}^{2}=8.575 \mathrm{~m}^{2}$

The total available energy inside the aircraft cabin from RF pulses emitted by the maximum dominant emitter $(\mathrm{f}=2.875 \mathrm{GHz})$ was found to be less than $0.1 \mathrm{~mJ}$. Even if this total energy could have been focused into a single discharge event, it was still below the generally accepted estimate of the minimum energy level $(0.2 \mathrm{~mJ})$ required to achieve fuel vapor ignition [4]. Further details of the analysis may be found in [5].

\section{TWA-800 Electromagnetic Environment versus Standard HIRF Environments}

The "Normal" and "Fixed Wing Severe" electromagnetic environments, defined in the soonto-be released FAA Advisory Circular / JAA
Advisory Material Joint (20.1317 Final Draft 8, March 1998) were compared with the JSC-derived TWA-800 environment. The results are shown in Figure 2. The draft AC/AMJ 20.1317 contains the following definitions:

- "The Normal HIRF environment is an estimate of the electromagnetic field strength level in the airspace on and about airports/heliports in which routine departure and arrival operations take place. This estimate considers the operational characteristics of the high peak power microwave transmitters, which typically do not operate continuously at the maximum output levels."

- "The Fixed Wing Severe HIRF environment is a worst case estimate of the electromagnetic field strength levels in the airspace in which fixed wing flight operations are permitted."

From Figure 2, it can be concluded that the JSC-derived TWA-800 environment was far less severe than that encountered in routine departure and arrival operations.

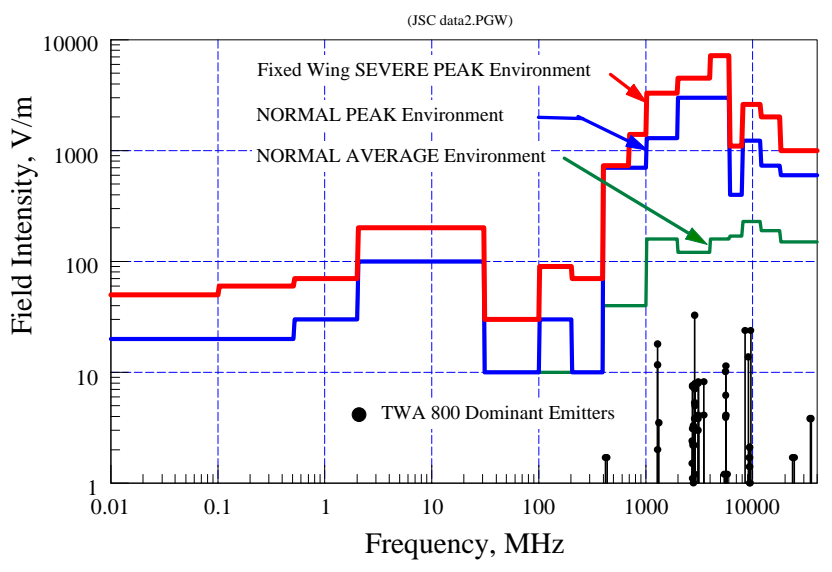

Figure 2. JSC TWA-800 Environment vs. Proposed AC/AMJ 20.1317 HIRF Environments

\section{Numerical Estimation of Coupling to FQIS Wiring}

To provide an estimate of how much energy could actually be coupled to the FQIS wiring within the passenger cabin from external sources (ie. B(f)), 
numerical modeling was used. The B-747-100 fuselage was assumed to be a large rectangular cavity with rectangular windows on each side. The cavity was assumed to be homogeneous and lossless, with no seats or other structures present. A new, NASA-LaRC developed numerical simulation technique, using a rectangular cavity Green's function and the integral equation method, estimated electromagnetic threats to the CWT due to external electromagnetic sources. The Modal/MoM (method of moments) code was validated through agreement with other analytical techniques and measurements. The Modal/MoM approach resulted in a lower number of unknowns compared to other numerical methods, such as the finite element method (FEM) and finite difference time domain (FDTD) methods. Therefore, this new approach is able to solve the large-size problems up to frequencies of 1-2 GHz. When applied to the available energy from the $1.294 \mathrm{GHz}$ emitter source, the Modal/MoM approach estimated that CWT FQIS coupled energy levels were several orders of magnitude less than the maximum available energy. Details regarding the new analysis tools and their application to this problem may be found in [5] and [6].

\section{Internal Analysis (Experimental)}

The threat from PEDs carried aboard the aircraft did not lend itself to the same computational analysis as for external threats. First, virtually all PED sources transmit in a continuous or continuously modulated fashion. Thus, the threat could not be evaluated in terms of energy. Most widely known data regarding fuel-vapor ignition hazards are given in terms of energy, not RF power. Second, there is the potential for near-field direct illumination of FQIS wiring with sources internal to the aircraft. For the external source problem, indirect illumination was the only option (via window. Direct illumination quickly becomes dominant for close proximity coupling, especially in an electromagnetically lossy environment like an aircraft passenger cabin. Direct coupling is highly dependent upon very specific boundary conditions and will vary greatly with frequency, which makes it exceedingly difficult to computationally model in an aircraft system.
Beginning again with Equation 1, it was necessary to quantify the PED threat in terms of power $(A(f))$, establish a "path factor" $(B(f))$ for the lowest coupling loss between a passenger cabin PED and the FQIS CWT connector, and determine the minimum RF stimulus required to cause an ionization discharge or significant heating event within the CWT (C(f)). It is important to note that an "event" was taken to be the detection of any discharge event. In practice however, higher power would likely be required for igniting fuel vapors. NASA TM-2000-210077 [7] was completed in support of the investigation, and endeavors to supplement the traditional understanding of electrical breakdown, heating and combustion with currently available information regarding aircraft fuel-vapor ignition by RF sources.

\section{PED Emissions $(A(f))$}

In 1996, intentionally transmitting PEDs such as cellular phones, garage door openers, remote control toys, FM wireless microphones, handheld radios (citizen's band, police, fire, business, maritime, etc.), cordless phones and keyless entry transmitters could easily be found among the traveling public. The FAA recommends prohibiting operation of intentionally transmitting PEDs during flight [8], however, adherence to the rules cannot be guaranteed.

For this effort, threat information was gathered from three sources: typical device manufacturer's specifications, ANSI C63.18-1997 (for typical transmitters for radiated electromagnetic immunity testing of medical devices), and the Federal Communication Commissions (FCC) regulations.

It was found that intentional radiators occupy numerous frequency bands from $27 \mathrm{MHz}$ to $6 \mathrm{GHz}$, and that virtually all "portable" devices radiate less than $10 \mathrm{~W}$. It was also found that the power radiated from typical PEDs drops significantly for frequencies higher than $1 \mathrm{GHz}$. Details of the analysis are given in [5] and [9].

\section{Aircraft Measurements $(B(f))$}

At the time of this investigation, several Classic B-747-100 aircraft, about the same age as TWA-800, were being retired from service. Such 
an aircraft was located in Roswell, New Mexico, and was employed for the following four objectives:

- Measure input impedance characteristics of the FQIS at the CWT connector, for comparison to laboratory installation.

- Measure peak radiated/conducted coupling from passenger cabin to CWT FQIS wiring (B(f)).

- Measure reverberation characteristics of empty CWT for comparison with the laboratory reverberation chamber.

- Recovery of actual FQIS components for installation into NASA Langley's HIRF laboratory.

NASA LaRC researchers developed a custom instrumentation package to comprehensively measure CWT FQIS RF input impedance. The FQIS connection consisted of 4 copper paths. Impedance data for differential combinations of these terminals, plus each to chassis were measured. Based upon the PED emission data and the limited high frequency transmission line performance of FQIS type wiring, a frequency range of $300 \mathrm{kHz}$ to $1 \mathrm{GHz}$ was selected. The instrumentation included a vector network analyzer, specialized calibration adapters and software for rapid, automated measurements of each terminal combination. Details regarding the instrumentation, as well as standard DC resistance and capacitance measurements can be found in [5] and [10].

A particularly unique set of measurements was obtained for the maximum possible path factor $(\mathrm{B}(\mathrm{f}))$ between the passenger cabin and FQIS CWT connection, from $25 \mathrm{MHz}$ to $1 \mathrm{GHz}$. For this, a laboratory RF signal generator was swept continuously while transmitting through a broadband antenna positioned at numerous locations throughout the passenger cabin, directly and indirectly illuminating FQIS wiring under the floor and along the walls. A RF spectrum analyzer was used to measure maximum voltages induced upon the FQIS CWT conductors. In addition, radiated field measurements resulting from the passenger cabin source were also taken inside the fuel tank, using an antenna. These measurements were useful in establishing FQIS wiring as the dominant coupling path into the CWT for frequencies below $2 \mathrm{GHz}$. Details can be found in [5] and [9].

Even if filled with fuel, the aluminum aircraft fuel tank was expected to exhibit a high degree of electromagnetic reverberation. This was a concern for comparing aircraft vs. laboratory FQIS installations. The laboratory chamber was made of steel, not aluminum. While its overall volume was similar to the CWT, the overall dimensions were different, and the interior was not divided into subcavities (fuel bays). An actual CWT also has penetrations for fuel and vent lines that are not necessarily secure from electromagnetic leakage. Because of these concerns, detailed measurements of fuel bay cavity coupling factor, and fuel bay-tofuel bay coupling factors were measured on the aircraft. This data was subsequently used to scale laboratory radiated field measurements to that which would be observed in the actual aircraft. Details regarding these measurements may be found in [5] and [9].

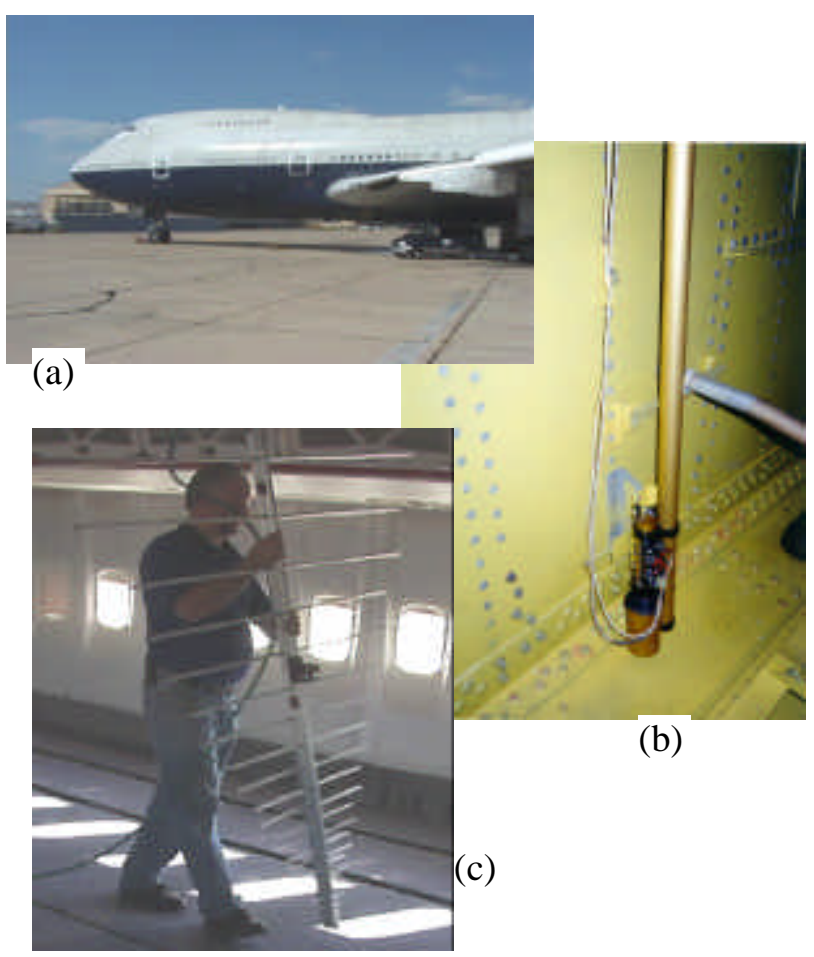

Figure 3. a) Retired B-747-100 aircraft in Roswell, New Mexico. b) Fuel quantity probe within CWT of retired aircraft. c) Path Factor measurements in B-747 passenger cabin. 


\section{Laboratory Measurements $(C(f))$}

All CWT FQIS components (including seven fuel quantity probes, compensator probe, the FQIS connector, and terminal strip) were removed from the retired aircraft in Roswell, New Mexico. The components were reinstalled into a NASA LaRC reverberation chamber, providing a non-hazardous test environment.

Careful consideration was required for facilitating voltage and current measurements, monitoring for arcing/sparking, and detecting localized heating. These requirements needed to be accommodated with an installation as electrically similar to the aircraft as possible. The system was backed with an aluminum sheet. Fuel probes and wiring were installed with separation distances from structure identical to that of the aircraft installation (to approximate the common mode impedances in the aircraft). Nylon cable clamps recovered from the actual aircraft CWT were used in the laboratory installation. The installation dimensions were confined to fit within the field-of-view of infrared camera and ionization detection instruments (as best as possible). The aluminum sheet was painted black to minimize infrared reflection. A shielded box was installed to isolate the FQIS connection from both the reverberation chamber (to prevent interference with the approximated CWT RF environment) and the RF generating equipment (for personnel safety). The final installation is shown in Figure 4.

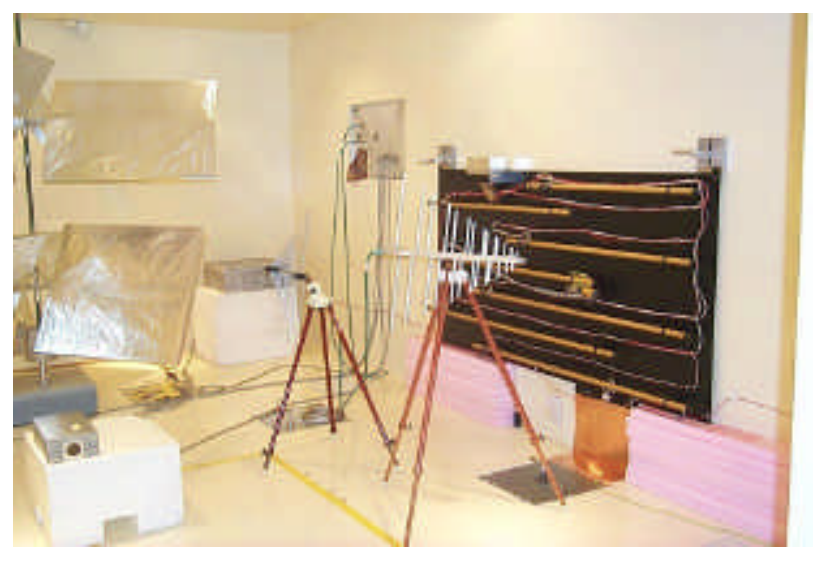

Figure 4. FQIS Components and Wiring Installed in LaRC Reverberation Chamber B

\section{Installation Comparability}

A major portion of the measurement effort was to establish limits of comparability between the aircraft and laboratory FQIS installations. Once this was accomplished, laboratory measurement of $\mathrm{RF}$ power required for ionization events/heating of CWT FQIS components and wiring could be correlated to the aircraft installation.

RF input impedance measurements were performed on the input terminals of the CWT FQIS connection in a manner identical to those performed on the actual aircraft. Analysis of this measurement data was particularly challenging. Because the fuel quantity probes were designed to be capacitive, and the wiring designed to be low-loss, the system impedances were highly reactive. From $25 \mathrm{MHz}$ to $1 \mathrm{GHz}$, slight changes in wire routing in the laboratory installation could cause very large input impedance variations at a given frequency. This would also be the case for different aircraft installations. In fact, a laboratory test at the Naval Surface Warfare Center (NSWC, Dahlgren, VA) demonstrated that fuel probe resonant frequencies changed dramatically with fuel level. Because of these factors, it would be impossible to characterize the CWT FQIS at a specific frequency, and expect similar results in the laboratory (or on another aircraft, or even on the same aircraft with a different amount of fuel). Fortunately, the goal was not to characterize the FQIS at a specific frequency, but to establish electromagnetic comparability to the laboratory installation in a general sense (ie. as good as any other aircraft installation). To accomplish this goal, statistical analysis was combined with a polar "Smith Chart" graphical plotting technique, resulting in a novel analysis tool for establishing comparability of input impedance. This analysis was useful in demonstrating validity comparing the laboratory CWT FQIS installation to that of the aircraft. Details may be found in [5] and [10].

Laboratory reverberation chamber cavity coupling factor measurements were also performed in a manner identical to those on the actual aircraft. A scale factor was computed for comparing the radiated field environment between the laboratory chamber and the aircraft CWT from $25 \mathrm{MHz}$ to 6 GHz. Details may be found in [5] and [9]. 


\section{Detailed Characterization of Laboratory FQIS Installation}

Aircraft measurements established that an RF source located in the passenger cabin coupled to the CWT mostly via the FQIS connection.

The FQIS provides 4 copper paths by which to introduce RF power into the CWT (LO Z, LO Z Comp, HI Z, HI Z Shield). This results in 4 common-mode paths (each line to chassis), in addition to the differential combinations. The largest loop areas, and therefore the dominant modes for coupling externally induced signals were from the common mode paths. By design, the $\mathrm{LO} \mathrm{Z}$ and LO Z Comp conductors are connected to the outside cylinder, while the $\mathrm{HI} \mathrm{Z}$ conductor is connected to the inside cylinder of the fuel probes. Because of the large surface area between these exposed conductors, laboratory measurements included these 2 differential, plus the 4 common mode excitations (LO Z-to-Chassis, LO Z Comp-toChassis, HI Z-to-Chassis, HI Z Shield-to-Chassis, LO Z -to-HI Z and LO Z Comp-to-HIZ).

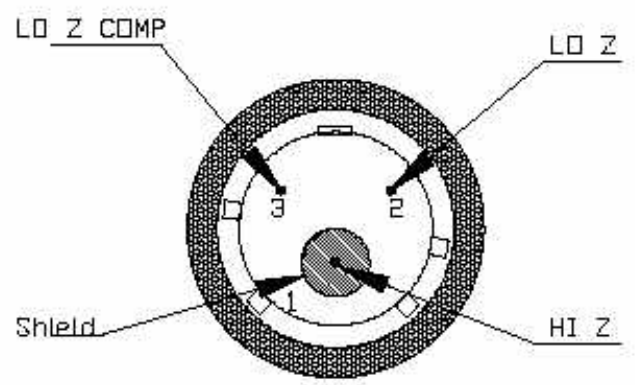

Figure 5. FQIS Connector

Using a vector network analyzer and specialized high-frequency voltage and current probes, the entire laboratory FQIS installation was characterized in terms of voltage and current induced when excited by each of the 6 excitation modes, at frequencies from $1 \mathrm{MHz}$ to $1000 \mathrm{MHz}$, at each of at least 10 locations. From the measurement data, RF power applied at two particular excitation modes (LO Z-to-Chassis, LO Z Comp-to-Chassis) were found to produce maximum enhancements at two specific test locations (Pos. \#2, max current: HI Z-to-Chassis; Pos. \#6, max voltage: LO Z Comp-to-Chassis), respectively. (See Figure 6.) At location 6, voltage enhancements up to 22 times higher than if the RF power was applied to a matched RF termination were measured. More details may be found in [5].

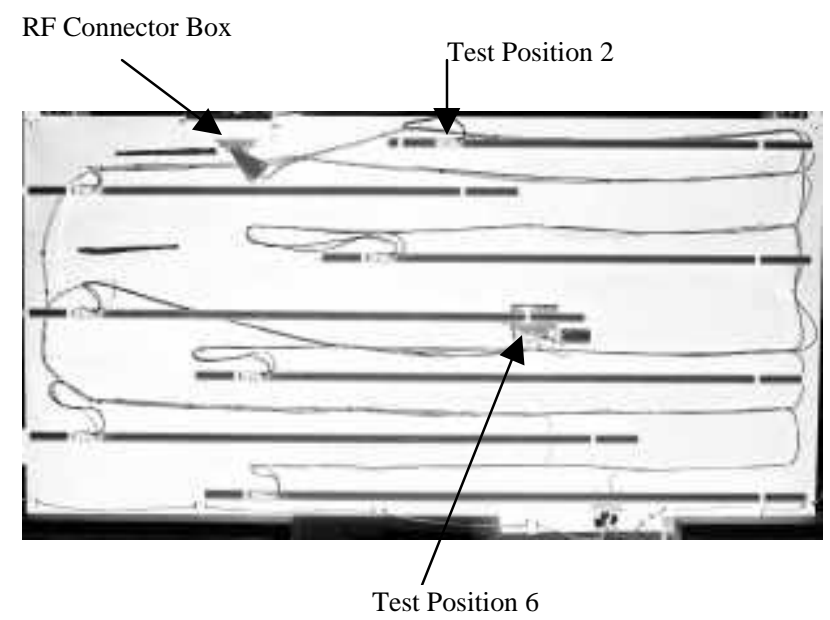

Figure 6. Laboratory FQIS Current/ Voltage Enhancement Locations

\section{Laboratory testing for discharge, excessive heating $(\mathbf{C}(\mathbf{f}))$ \\ With all CWT FQIS components installed in} the reverberation chamber, and data to establish comparability between the laboratory and aircraft installations, it was then possible to apply increasing levels of RF power, and monitor for a discharge or excessive heating event. Considerable effort was applied to the problem of detecting such events. The primary tool for detecting electrical discharge was a AMT MO-32 night vision scope, attached to a standard $8 \mathrm{~mm}$ video camcorder with low-lux light capability. The primary tool for measuring heat emissions from the FQIS was an Inframetrics model 600, nitrogen-cooled thermal imaging system. A photograph of these tools is shown in Figure 7, and details regarding their use may be found in [5].

To simulate the condition of estimated worstcase PED coupling onto FQIS wiring (based upon aircraft measurements of maximum possible path factor (B(f))), $100 \mathrm{~mW}$ of RF power (from $1 \mathrm{MHz}$ to $1 \mathrm{GHz}$ ) was applied to the three dominant excitation modes (LO Z-to Chassis, LO Z Comp-toChassis, HI Z-to Chassis). Testing at this level did not yield any evidence of discharge or detectable heating. 


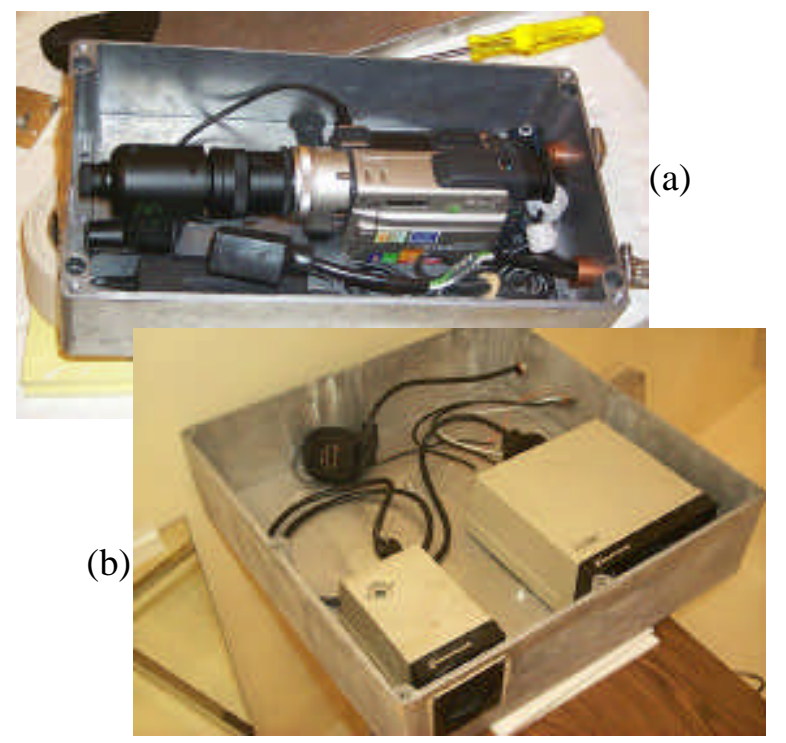

Figure 7. (a) AMT MO-32 Night Vision System. (b) Inframetrics Model 600 Thermal Imaging System.

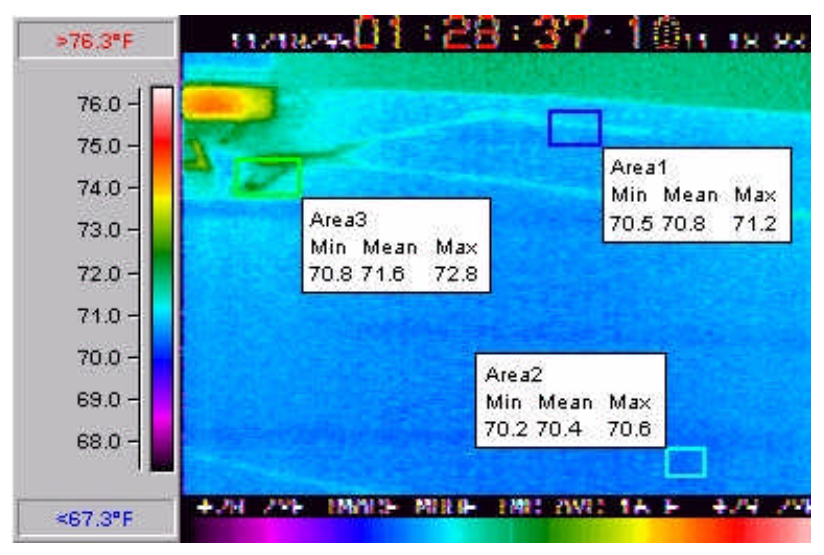

Figure 8. Inframetrics Thermal Imager Display

To simulate the condition of highest power PEDs with no path loss, a minimum of $10 \mathrm{~W}$ of RF power (from $1 \mathrm{MHz}$ to $1 \mathrm{GHz}$ ) was applied to the three dominant excitation modes (LO Z-to Chassis, LO Z Comp-to-Chassis, HI Z-to Chassis). Figure 8 shows the thermal image display, when 24 to $65 \mathrm{~W}$ was applied across LO Z Comp-to-Chassis. Temperature measurement windows were defined at the peak current enhancement location (TP-2, defined as "Area1"), and at the peak voltage enhancement location (TP-6, defined as "Area2"). It can be seen that heating at these locations was negligible. A temperature measurement window was also defined at wires exiting the FQIS connector shielded box ("Area3"). Temperature increases of about $5^{\circ} \mathrm{F}$ were measured from within the shielded box.

Testing at this level did not yield any evidence of electrical discharge, except when intermittent faults were introduced.

\section{Fault Testing}

In practice, it is feasible that conductive debris may sometimes find its way into aircraft fuel tanks. Because of this, it was decided that the laboratory testing should also include an intermittent short condition at the location of maximum voltage enhancement.

A piece of brass wool was bonded to the supporting structure and made to intermittently contact a FQIS probe terminal (by applying forced air through a rotating plastic fan assembly). Two terminals on the compensator probe (TP-6) were determined to provide maximum voltage enhancements. They were the HI Z terminal (with LO Z-to-Chassis excitation), and the LO Z COMP terminal (with LO Z Comp-to-Chassis excitation). An intermittent short from one of these locations to chassis could be expected to develop a break-spark condition with the lowest applied RF power. A photograph of the arrangement is shown in Figure 9a. Figure 9b shows a still-image of a videotaped discharge event as viewed by the night vision system.

Figure 10 shows each frequency and power level at which a discharge event was detected for both excitation modes, along with the worst-case estimated coupled power from PEDs located within the passenger cabin. The testing revealed that a strategically placed, intermittent short circuit could cause FQIS discharge events with as little as $1.5 \mathrm{~W}$ of applied RF power in the PED frequency range for Citizen's Band radio (27 MHz). However (also as shown in Figure 10), 1.5 W was at least 10 times greater than the maximum possible PED threat, when adjusted for path loss.

\section{Supplemental Analysis Regarding External Threats Below $30 \mathrm{MHz}$}

From the fault testing, it was found that only $0.17 \mathrm{~W}$ of power was required for generating 
discharges in the laboratory installation at a frequency of $6.8 \mathrm{MHz}$. For this frequency, the most likely RF source would have been the on-board HF radio. However, it is known that the TWA- $800 \mathrm{HF}$ radio was not transmitting during its flight. The threat analysis, therefore, needed to consider sources external to the aircraft. (Commercially available PEDs were determined to be insignificant in terms of radiated power below $25 \mathrm{MHz}$.) To assist in this analysis, the JSC provided supplementary data showing all dominant transmitters contributing to the TWA-800 environment below $30 \mathrm{MHz}$. By evaluating the entire B-747-100 airframe as an efficient and perfectly tuned dipole antenna, it was calculated that TWA- 800 could not have coupled more than $0.015 \mathrm{~W}$ of power from any of these sources. See [5] for analysis details.

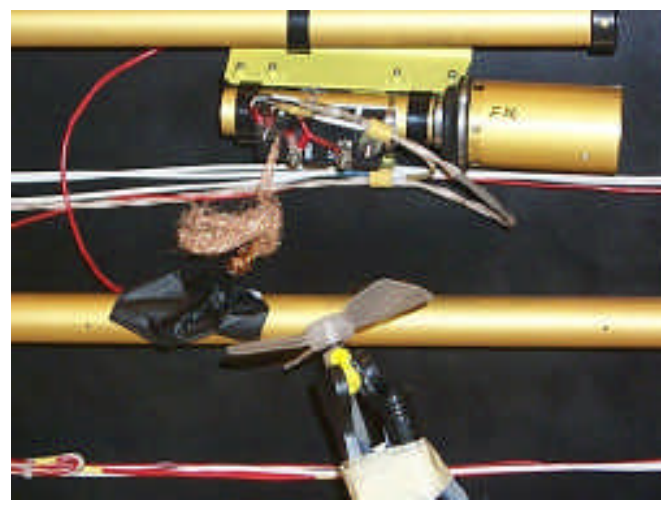

(a)

\section{Detected Sparking}

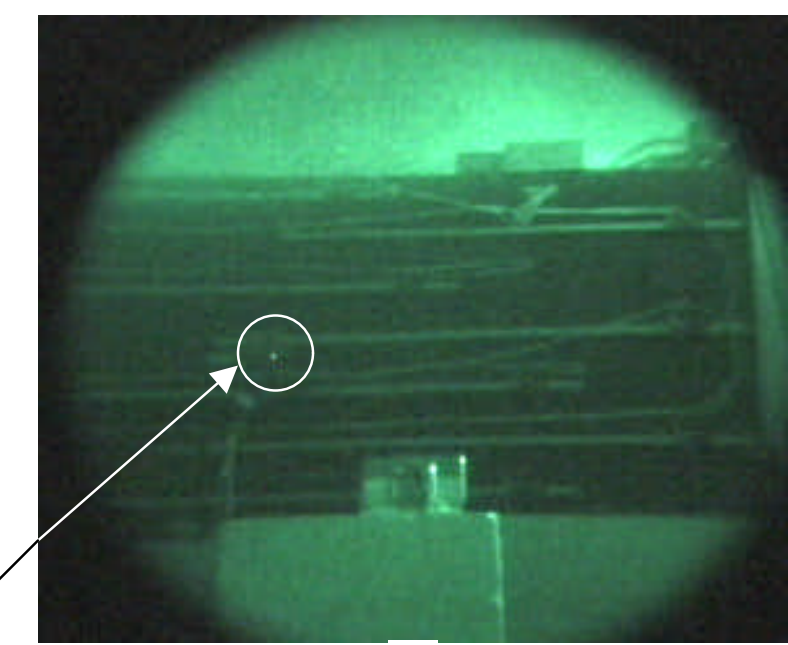

(b)

Figure 9. (a) Intermittent short condition at voltage enhancement location TP-6. (b) Night vision system display showing a discharge event at TP-6. (Note that this image was taken through a mirror, and is therefore reversed.)

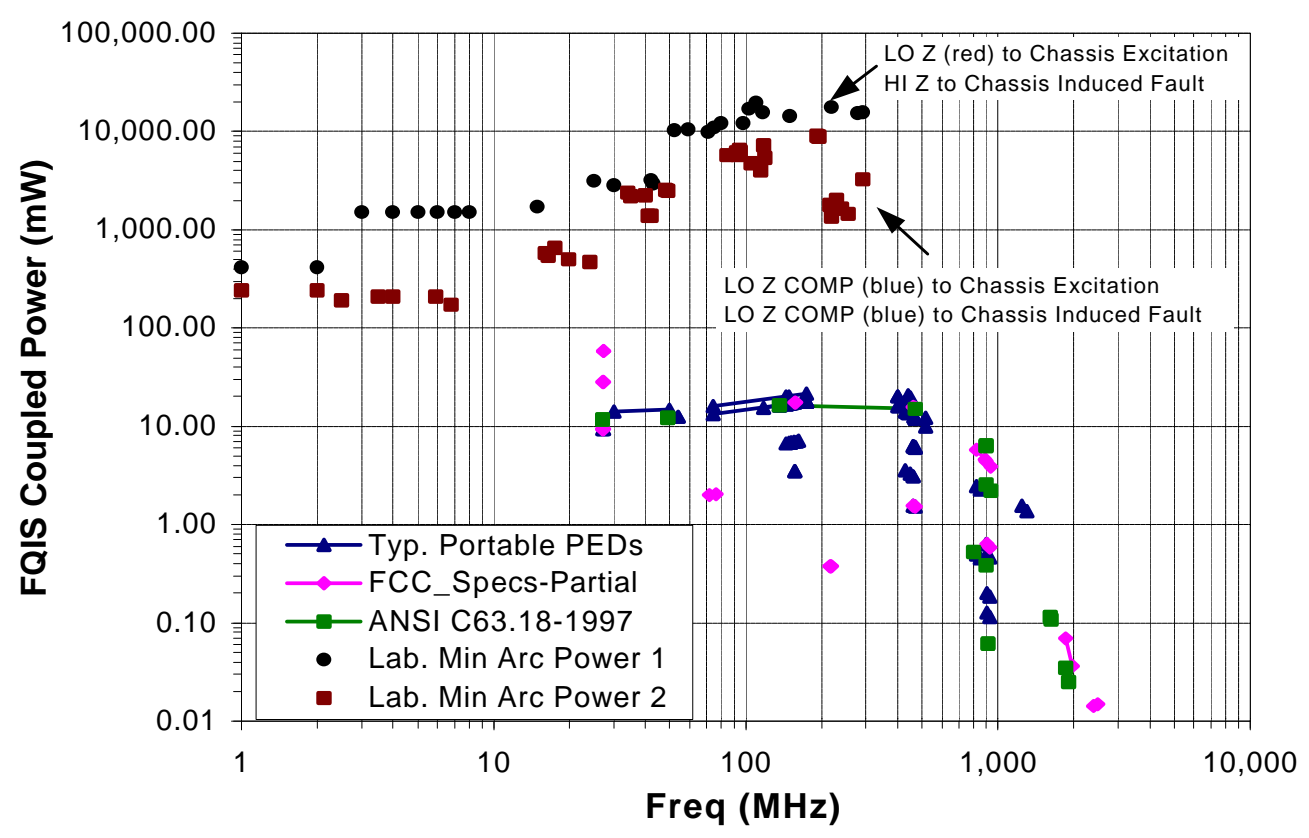

Figure 10. FQIS minimum observed arc/spark levels with different excitation and induced faults. Also shown are PED threats, adjusted for passenger cabin-to-CWT FQIS connector path loss. 


\section{Conclusions, Perspective}

The maximum available energy inside the TWA-800 passenger cabin from external sources identified by the JSC was less than $0.1 \mathrm{~mJ}$. A new NASA LaRC-developed numerical analysis code estimated that the CWT FQIS coupled energy levels were several orders of magnitude less than the maximum available energy. Therefore, these external sources could not have caused CWT ignition.

It was determined that typical, commercially available PEDs in 1996 radiated less than $10 \mathrm{~W}$ of power between $27 \mathrm{MHz}$ and $1 \mathrm{GHz}$ frequency. A minimum power level of $10 \mathrm{~W}$ was applied to the FQIS terminals in the laboratory installation over a frequency band of $25 \mathrm{MHz}$ to $1 \mathrm{GHz}$, with no electrical discharge or significant heating detected. A supplemental test, using an intermittent short circuit at a FQIS location selected for peak voltage enhancements, induced discharge events with as little as $1.5 \mathrm{~W}$ of applied RF power. Considering the passenger cabin-to-CWT FQIS coupling loss, this power was at least 10 times greater than the maximum PED threat, even if the PED transmitted from an optimal coupling location in the passenger cabin.

Laboratory testing to determine the absolute minimum power required for a discharge was extended from $25 \mathrm{MHz}$ down to $1 \mathrm{MHz}$ frequency. This testing revealed that an intermittent short circuit could cause discharge events with as little as $0.17 \mathrm{~W}$ of power at frequencies below $10 \mathrm{MHz}$, when applied to the FQIS location selected for peak voltage enhancements. Analysis revealed that the whole TWA-800 aircraft could not have coupled more than $0.015 \mathrm{~W}$ of power in this frequency range from the surrounding electromagnetic environment, at the time of the accident.

This effort focused exclusively on non-aircraft generated electromagnetic signals. Such signals are far more likely to interfere with, and even damage, sensitive aircraft navigation sensors, displays, processors, and communication equipment, than to create sparks within the CWT.

\section{Acknowledgement}

This work was supported by the NTSB, and the Aviation Safety Program Office at NASA Langley Research Center, Hampton, VA.

\section{References}

[1] Scarry, Elaine, 4/9/1998, "The Fall of TWA800: The Possibility of Electromagnetic Interference", The NY Review of Books, pp. 59-76.

[2] Macrae, M., D. Hughes, 1/1999, "TWA Flight 800 Electromagnetic Environment”, United States DoD JSC Report JSC-CR-99-006,

[3] DoD Interface Standard, MIL-STD-464, 3/18/1997, "Electromagnetic Environmental Effects Requirements for Systems", Sec A5.8.2

[4] Fisher, F. A., J. A. Plumer and R. A. Perala, 1990, Lightning Protection of Aircraft, Lightning Technologies Inc., p. 174.

[5] Ely, J.J., T.X. Nguyen, K.L. Dudley, S.A. Scearce, F.B. Beck, M.D. Deshpande, C.R. Cockrel, 3/2000, "Investigation of Electromagnetic Field Threat to Fuel Tank Wiring of a Transport Aircraft", NASA TP-2000-209867

[6] Deshpande, M. D., C. R. Cockrell, F. B. Beck, 10/2000, "Estimation of Electromagnetic Energy Coupling to a Wire Residing Inside a Transport Aircraft Due to External Radiating Sources", Digital Avionics Systems Conference (DASC) Proceedings, Paper \# 236

[7] F. A. Fisher, 3/2000, "Some Notes on Sparks and Ignition of Fuels", NASA/TM-2000-210077.

[8] Accardi, T. C., 8/20/1993, "Use of Portable Electronic Devices Aboard Aircraft", FAA Advisory Circular AC No: 91.21-1

[9] Nguyen, T. X., K. L. Dudley, S. A. Scearce, J. J. Ely, R. E. Richardson, M. O. Hatfield, 10/2000, "RF Coupling into the Fuel Tank of a Large Transport Aircraft from Intentionally Transmitting PEDs in the Passenger Cabin", DASC Proceedings, Paper \# 234

[10] Scearce, S. A., K. L. Dudley, T. X. Nguyen, J. J. Ely, 10/2000, "The Use of Transmission Line Impedance Measurements to Determine Electromagnetic Comparability of FQIS Wiring Installations", DASC Proceedings, Paper \# 235 